\title{
A Methodology of the Imagination
}

\author{
Dr Andrew Armitage (Corresponding author) \\ Anglia Ruskin University, Cambridge, UK \\ Tel: 44-01-245-493-131Ｅ-mail: andrew.armitage@anglia.ac.uk
}

Received: March 21, 2012

Accepted: May 17, 2012

Online Published: June 28, 2012

doi:10.5430/jbar.v1n1p1

URL: http://dx.doi.org/10.5430/jbar.v1n1p1

\begin{abstract}
This paper proposes that management research educators are in need to develop alternative pedagogical approaches to explore the realities of organisational life, and uses Sullivan's (2005) "Visual Knowing" and dialogue as being central to "know the world". It advances the idea of the poetics of imagination that is located within the phenomenological lens of Gaston Bachelard's The Poetics of Space as being an alternative mode of enquiry and analysis, for those wishing to explore organisational realities that go beyond the boundaries of traditional management discourse, and that a methodology of the imagination is possible when combined within the ideas of Paulo Freire's dialogical process. Examples taken from classroom practice show how the dialogical imagination is fundamental to the formulation of research problems, and concludes this is central to a more radical pedagogical approach not often encountered in the research process, being a challenge to traditional methods of gaining access to organisational realties.
\end{abstract}

Keywords: Poetics, Images, Imagination, Dialogue

\section{Introduction}

Greene (1978:12) describes how discovery has been taken out of learning in many teaching/learning situations noting 'The self as participant, as inquirer, as creator of meanings has been obliterated'. However, as Latta (1994) states 'Rather than conformity, being rewarded, in [these] classrooms, difference is not cause for alarm but celebration'. Making students aware of wider political, cultural, and social contexts and their impact upon organisational life can lack relevance, and if taught without reference to situationality can lead to alienation. However, it has been argued that if we are to explore pedagogic practices that push, and go beyond the boundaries of traditional Critical Management Research, then alternative modes of enquiry need to be developed to unlock the "hidden realties" of organisational life and practice. For example, Boje and Al Arkoubi (2009) have suggested that Critical Management Research should draw on an eclectic range of critical theoretical perspectives to explore its future practices (see, for example Voss, 2009). However, Linstead (2000:84) has noted that, 'Yet across the social sciences, few attempts to radicalise the forms in which social investigation finds its expression have been attempted outside of social anthropology'. Furthermore, expressive forms of reporting organisational reality, such as storytelling, and poetry, is still under theorised, and under used (Bolton, 2001).

However, despite the foregoing, others have used artwork to unpack historical issues and metaphors (Kent, 2003), and to 'tease out possibilities, demolish preconceptions, disrupt complacencies, challenge decision making, and find creative comfort among incongruities' (Sullivan, 2005:197). It can therefore be argued that all human activity can be described as an artistic endeavour (Boal, 1974), where individuals construct their realities, shape ideas, and actions, for example through the representative media of drawings, and imagery that are part of a broader system of cultural forms that play an active role in social, political, and cultural (Mitchell, 1994). All research according to Sullivan includes a phase where information is encountered, and critiqued to create representations that assist further inquiry, stating that 'Responding to information in an insightful fashion through constructive dialogue means that private views need to enter into public discourse, for it is within the interpretive community of the field that alternative visions are most keenly felt' (Sullivan, 2005:215). Sullivan proposes a framework of "Visual Knowing" that captures the various ways visual arts thinking has been described, in which a historical perspective is central to its construction. The core of Sullivan's framework is concerned with five issues: the Transcognition, the Practical-Theoretical, the Creative Practice, the Artistic Content, and the Artist Self as Site. As such, Sullivan is antithetical to modes of research inquiry that conform to the 'general domains of research associated with the empiricist, interpretive, and the critical paradigms' (Sullivan, 2005:128). As Sullivan (2005:115) notes 'To create, 
the researcher has to enter into the realm of imagination, to take on the possible, as well as the plausible and the possible'.

Sullivan's framework of "Visual Knowing" is thus an attempt to situate the artist as researcher central to the creative process within a recursive dialogue in the creation of cognitive structures, and a coalition that involves 'an ongoing dialogue between, within, and around the artist, artwork, and setting, where each has a role in co-constructing meaning' (Sullivan, 2005:130).

For Sullivan, the traditional dichotomies in research practice come under challenge, where, issues and ideas are reconceptualised as concerns and interests change focus. For example, process and product become interest in purpose, practice, and progress; knowing what and how become interests in creating, critiquing, and constructing; form and content become interests in images, ideas and contexts; theory and practice become interests in structure, agency, and action (Sullivan, 2005). Sullivan thus provides an alternative conceptualisation of the research process, albeit from the position of an artistic endeavour that challenges the traditional notions of what counts and can be accepted as valid knowledge and reality. Part of Sullivan's framework concerns interests in images, ideas, and concepts, which are often absent from the lexicon of management research discourse, approaches, and methodologies. This provides an alternative exploration of reality, which is antithetical to scientific method, and the traditional approaches and methodologies found within the social sciences. If imagination is to play its part in the conceptualisation of a research topic and its conceptual framework, then the metaphorical model has to be taken as a primary means of investigation, and for images to speak in academic work, that refer to Jung's definition of the psyche as a 'series of images in the truest sense' (Angelo, 2005:15).

\section{Imagination and reverie: Towards a methodology of imagination}

Imagination, (from im-ago 'I act from within'), whether one considers it from Neo-Platonist, Romantic, or archetypical psychological perspectives, is the mode in which the soul reveals its nature through the language of symbol and metaphor. As such, it is creative and will always seek to amplify and enhance that which it touches (Voss, 2009). This is exemplified by Bachelard's poetics of the imagination that provides a methodological path to explore alternative realities. Bachelard's approach, through poetry, shows that nothing is stable, and everything is in flux. It is only through the phenomenological method, and engagement with the imagination and reverie, that we can hope to access an authentic reality. As Bachelard (1958:14) states 'Contemporary poetry, has introduced freedom in the very body of language. As a result, poetry appears as a phenomenon of freedom', and Bachelard (1958:16) notes, 'The poetic imagination does not express what remains foreign to us, all human experience and action seeks to speak through the word, to write', and to 'give order to reverie and thought', where 'the poetic imagination being a mode of aesthetic literary expression, and essential in the production of images, and the way we encounter space' (Bachelard, 1958:16).

Bachelard (1958) sees space as imagined, and poetic, describing his method as recourse to the phenomenology of the imagination' and 'understood as a study of the phenomena of the poetic image when it emerges in to the consciousness as a direct product of the heart, soul, and being of the person. For Bachelard the conception of space is a place constituted by the imagination that is bounded and real, and is not a place where we live our lives and fill it with emptiness, and mere abstraction. Bachelard's pedagogy of the imagination, is a poignant reminder that we must become conscious beings, socially active agents, striving for originality, and that the essence of what a creative pedagogy should aspire to be as 'In analyzing images of immensity, we should realize within ourselves the being of pure imagination. It then becomes clear that works of art are the by-product of the existentialism of the imagining being' (Bachelard, 1958:124). As Uhrmacher (2004:99) notes 'Man is not merely a spectator' says 'he is rather the world's stage upon which great cosmic events continuously play themselves out'.

Bachelard (1958:7) captures the mood of this approach as being cast into the world, where an individual becomes aware of their being, and one that is described, defined, and is circumscribed by the physicality of its existence. However, a phenomenology of pedagogy is a "house" where consciousness dwells within the boundaries of the mind, boundaries that are mutable, fluid, and permeable, but in the "imaginal" space of the poetic image, a real space that is bounded, but a place where our actions and lives are not just constructed. Bachelard (1958: xxxv) defines bounded and imaginal spaces as "Topophilia", which are "The places of the determination of human value, of the sorts of space that may be grasped, that may be defended against adverse forces, the space we love. For diverse reasons, and with differences entailed by poetic shadings, this is eulogized space'. As Slater (2004:51) notes 'A new space is a transformation of a worldview. Questions of value, worth, and usefulness to the community are part of the creation of alternative space, but the product can be an alternative society that engenders public involvement in its own 
evolution'. Marcuse (1978:41) has eulogized about space and the aesthetic as being 'Designated space where the experience of the freedom is recreated'

If we are to give imagination legitimacy in organisational and business life then we must be prepared to accept that the constructivist meaning-making activity of an individual has a valid role to play in truth making, and its own claims to an authentic reality (see, for example Ragsdell, 2000). Ricoeur (1975) called authentic reality productive imagination, stating that if "we start with an image without an original, then we may discover a second type of ontology which is not the ontology of the original, but....the ontology displayed by the image itself, because it has no original'. This is might not be problematic, and not an easily accepted position for those who adopt realist, or traditional interpretive research predispositions. A methodology of the imagination demands that we go beyond the world of experience, determined as it is by an individual's perception of reality, and ultimately translated through their senses, and to enter a reality that cannot be readily experienced by others, who are not privileged to experience what another individual sees, feels, or puts into a personal language. As Alvesson and Skoldberg (2000:89) state we encounter the world 'first by imagery and then afterwards put the similarity into words'. There is always a poetic "aura" of images around the words, and which image we choose depends on the angle of view, the perspective taken, and is thus subjectively conditioned. The importance of the picture or image is also strongly interlined by the French "sociology of the imaginary" (Fourastie and Joron. 1993), which is devoted to a hermeneutics of everyday life, and as Lalli (1989:111) notes 'Indeed, everyone's social experience is an unending work of metaphorical, imagery production' (See also Tacussel, 1993).

The foregoing raises questions as to how we might enter into "another's" conscious activities and will naturally attract the criticisms of those who uphold ontological and epistemological positions normally associated with the empiricism of science, and social constructionist approaches of the social sciences. However, it can be argued that if we are to enter another's inner thoughts then this can only be achieved within the context of emancipation and democratic learning environments of the dialogical process. Here, where student-student, and teacher-students relationships are based upon mutual respect in order to explore the realities of individuals within their social, political, and cultural settings (see, for example, Freire, 1970; Giroux, 1988). It has been argued that dialogue becomes not merely a mode of construction, creation, and an exchange of ideas, but an approach that constructs an unfolding reality between those who engage in its process, and a place where conscientization is born (see Freire, 1972). Dialogue is thus the pedagogical space, where reality is socially constructed by those who partake in its process (Freire, 1970), and provides the bridge between constructivist and constructionist ontology's, between an individual's psychological construction of reality, and the co-production of reality with other individual's (Patton, 2002).

Studies that take a dialogical perspective focus upon the realities of individuals in their social, political and cultural contexts and 'includes focusing on the constructed nature of people and reality, emphasising language as a system of distinctions which are central to the construction process, arguing against grand narratives and large scale theories [and] systems ' (Alvesson and Deetz: 2000:36). As such, dialogical studies according to Alvesson and Deetz (2006) reject Marxist and functional conceptions of the world where they are regarded as theories of domination and oppression, thus eschewing the power/knowledge nexus, and the role of powerful elites in the domination of discourse. Central to the research process for dialogic studies are the foregrounding of narratives, fiction and rhetoric. These focus upon the fragmentation of discourse, and like the critical theorists are concerned with the domination and asymmetry of power relations. However, unlike the critical theorists, dialogical studies are concerned with domination that is considered mobile, and situational, and "not done" by anyone or one particular person on another, thus group and individual identity cannot be regarded as being fixed or homogenous (Alvesson and Deetz, 2006). Therefore, those who adopt a dialogical perspective in their studies aim to reclaim and expose conflicts of domination that suppress those without a voice in their 'everyday realities, meaning systems, and self-conceptions of, and the enhancement of local forms of resistance' (Alvesson and Deetz, 2000:36). They also reveal the hidden power structures and resistance in the complex nexus of power-knowledge relationships. Unlike critical theory, dialogical studies give attention to the creation of a space of recovery whereby individuals and groups who are marginalised by the powerful dominating elites can reclaim their identity, transformative powers, and give meaning to their lives.

As such, dialogue is the place where individuals meet to exchange and confide in others their concerns, and issues, and it is a place to mediate, gain mutual support, and friendship through ethical, and dignified discourse. Unpacking such encounters transcends instrumental value systems, but rather they are concerned with sharing, exploring shared meanings, and understanding "how the world works", and how it can be negotiated for the common good, and for common purposes. In so doing, dialogue becomes a space for play, freedom, and creativity. It is the space where discourse moves allows creativity to flourish, and those involved in such spaces of creative freedom can without fear 
of ridicule, talk of the unspoken, and think the unimaginable. Latta (2004:93) notes that 'The attunement to the creating process is the nature of aesthetic encounters. Initiating, sustaining, and enhancing links between students, and learning through aesthetic encounters is central in the classroom'. As Freire (1998:33) notes 'Only in this way can we speak authentically of knowledge that is taught, in which the taught is grasped in its very essence and therefore learned by those who are learning'. This also demands that educators have to submit themselves to a similar attitude whereby they acquire new knowledge in the process of teaching, not just the facts of subject knowledge, but also knowledge of the process and creation of knowledge-in-transformation (Shor and Freire, 1987). Organisational dialogue as pedagogic space needs to commence with an exploration of the doubts and fears that participation will entail. Calvino (1998) captures such an approach as the dialogical imagination where he states 'This is of course a kind of pedagogy that we can only exercise upon ourselves, according to methods invented for the occasion, and with unpredictable results'.

\section{The dialogical imagination in practice}

\subsection{The context of the dialogical imagination}

It can be argued that organisations are places where two cultures exist. On the one hand there is the official cultural norm's propagated by organisational customs, working practices, and behaviours. On the other there is a culture of silence that operates at a subterranean level of organisational life (see, for example, Greenberg and Edwards, 2009). However, research into the silent culture of organisations still remains underdeveloped, and what has to date been published tends to adopt a natural scientific attitude to their research designs and reporting mechanisms, (for notable exceptions see Detert and Edmondson, 2006; Edwards and Gardner, 2007; and Milliken et al, 2003, Morrison and Rothman, 2008; Premeaux and Bedian, 2003). However, all of these studies whilst using qualitative research designs do not offer those taking part in the study any hope of empowerment and escape from the oppressive official organisational culture and rhetoric, and lack any notions of the concept of conscientization, the process where an individual develops their sense of being a subject, and of apprehending their ability to intervene in external reality (McCowon, 2006). The culture of silence and intervening in realty to transform the world was central Paolo Freire's concept of conscientization, and dialogic practice. For Freire, the silent culture and his concerns for the oppressed was not only part of his pedagogical approach of human freedom, but was also at the heart of his methodological rigour as a researcher in the exploration of self and other, being predicated on the Hegelian concept of becoming, and the Marxist theory of praxis (action and reflection) as a means to gain authentic knowledge and reality of the world. Central to Freire's approach was the concept of conscientization and liberation, whereby individuals become critically aware of their true situation, intervene in its realty and take charge of their destiny, but as he acknowledged that for the oppressed change and taking control of their destiny was particularly difficult to put into practice as they belonged to "the culture of silence". As Freire noted there is no indivisible solidarity between humans and their world, and no dichotomy can be made between the two, and that 'Authentic reflection considers neither abstract man nor the world without men, but men in their relations to the world' (Freire, 1972:54), and that 'we are not only in the world but also with the world' that is 'essentially related to it' (Freire, 1972:51). Thus conscientization for Freire, together with the dialogical process was the means to unlock and challenge the culture of silence.

\subsection{The dialogical imagination: Methodological approach}

The production of conceptual frameworks can be a daunting aspect of the research act, especially in the formulation of research aims, objectives, and questions, and getting individuals to focus upon tightly thought out problems and "organisational puzzles" that can be realistically studied is not always as readily achieved as first thought. The production of conceptual frameworks whereby concrete organisational realities are translated into their more abstract entities and theoretical underpinnings can prove problematic, especially for "novice" researchers who sometimes bring their personal and organisational preconceptions, and institutional cultures into the research process without critical reflection and challenge, to produce conceptual frameworks can often prove to be a daunting task.

A strategy to overcome "mental blockages" in conceiving organisational realities is to combine artwork using image work, and dialogue groups in order to encourage students to think creatively about their organisations, and ultimately to produce their conceptual models and frameworks at the beginning of the research process. Sullivan's (2008) work mentioned previously, and the dialogical process, based upon Freire (1970) and Giroux's (1988) critical pedagogy underpin this approach. The formulation of research problems can be (even for mature students who have a good knowledge of how organisations work) a troublesome part of the research process. They often have difficulty conceptualising, and partitioning their thoughts towards a focal and singular set of issues, and when asked to construct conceptual frameworks, struggle to elevate their thought processes beyond the concrete realities that they are familiar with on a day-to-day basis. As such, teaching this aspect of the research process requires more 
imaginative approaches (than those traditionally adopted, and advocated by standard research methods textbooks. In other words, combining image work and dialogue as a teaching strategy challenges students to re-assess, and challenge more profoundly their preconceived notions of how their organisational realities work, and shows that the research process is not a "linear" process, but is rather a "messy" journey of discovery. Dialogue espouses a value and ethical approach that engenders dignity, honesty and trust built upon equitable personal relationships and offers creative approaches to establish common meanings and understandings. As Bohm et al (1991) state:

'In our modern culture men and women are able to interact with one another in many ways: they can sing dance or play together with little difficulty but their ability to talk together about subjects that matter deeply to them seems invariable to lead to dispute, division and often to violence. In our view, this condition points to a deep and pervasive defect in the process of human thought."

Dialogical research therefore focuses upon the power-knowledge nexus of human encounters, and the fragmentation and disunity of discourse. As such, studies that take a dialogical perspective focus upon the realities of individuals in their social, political and cultural contexts and 'includes focusing on the constructed nature of people and reality, emphasising language as a system of distinctions which are central to the construction process, arguing against grand narratives and large scale theories [and] systems" (Alvesson and Deetz 2000:36). As such, dialogical studies reject functional conceptions of the world which are regarded as theories of domination and oppression, and eschew the power/knowledge nexus and the role that powerful elites play in the domination of discourse. They are therefore a response to research practices that are grounded within modernistic processes, practices, and ideologies that deny individuals a voice in the research act. Their focus is instead being directed upon the "silent voices" who are "oppressed" by organisational domination of organisational life where generative themes (concepts) are produced by individuals, before being decoded into their concrete reality through words in the dialogical process, and within the confines of dialogue groups with other colleagues in order to help them problematize their social, political, and cultural situation (see, for example, Freire, 1970 and 1972). Therefore, dialogical studies give attention to the creation of a space of recovery whereby individuals and groups who are marginalised can reclaim their identity, transform, and give meaning to their lives in the shadow of those who reside within powerful (dominating) elites (Freire, 1970).

The study described here adopted a participatory research approach based on the methodology of Paulo Freire's concept of conscientization which is the process where individuals 'not as recipients, but as knowing subjects, achieve a deepening awareness both of the socio-cultural reality which shapes their lives and of their capacity to transform that reality' (Freire, 1972:51) and as means to explore and understand the culture of silence. Participants within their social, political, and cultural contexts move towards what he called critical consciousness by developing themes, which are central to their situation in order to generate words and issues related their existential experience. These themes are then shared with other participants in dialogue groups so they can be decoded with others thus enabling individual's to gain a greater understanding of their reality, and to re-consider how they might deal with their situation and as a way to change and deal with the issues that confront them. As Ryan (1974:36) notes 'In this way, little by little, by means of generative words, they stimulate the creative imagination'.

The sample consisted of twelve postgraduate students who were undertaking a research methods module prior to completing their dissertation, ten of whom worked in the public sector, and were invited to consider a single question: What is your organisation like? Students were asked to produce picture images of how they felt about or perceived their organisational reality, which were to be used to create conceptual frameworks for studying their own organisations, and they were then asked to present their images to each other in dialogue groups consisting of four to six fellow students in order to decode the contents of their images. This for some was a disconcerting request as it is contrary to the usual teaching rubric of "banking" (see, for example, Freire, 1970) whereby students are led towards specific methods of analysis, models, and frameworks by their tutor, and to allay any fears of vulnerability that they might have had to this request, re-assurances were given that any images and subsequent discussions of them would be kept within the confines of their dialogue groups, and would be reported anonymously.

\subsection{Findings}

When drawing their pictures without constraint, students produced images such as clowns, skateboards, racetracks and teams of athletes to illustrate their feelings, and perceptual responses as to how they conceived their organisational realities. Narrative labels and quotation balloons that included departmental and individual roles within their organisation also indicated their concerns with organisational communications networks and power blockages. The following are responses from students who were talking about how they felt about their organisations and as some of the extracts show that by drawing images of how they perceive their organisation it allowed them to 
reveal hidden (suppressed?) feelings of their organisational realties than perhaps might have been the case with traditional semi-structured interviews. For example, an unexpected and interesting observation was the general humour that participants approached the task and apparent "fun" experienced when producing the rich pictures. This may represent the creative element of producing drawings or even the "delinquent" element of revealing secrets of how their organisations actually work by representing emotional dissonance experienced in the workplace. As one student stated:

"This process is a cathartic experience - I have never thought of my organisation in terms of image work. Discovering who holds power and who "holds all the cards" in my organisation is something I do not consciously think about in the hurly-burly of my busy day".

Some students" "secret views" and emotional reactions were also articulated not only through their images, but also in how they described this to other students in their dialogue groups. For example, one student drew an image of their organisation in the form of a crucifix, and when asked why by a member of her dialogue group replied:

"This is how I feel - nailed to a cross, mocked, and left for dead. It's a kind of slow death as the organisation first suffocates, and then sacrifices those who do not have any form of hitting back, or are not empowered to think for themselves. For me to represent my organisation like this is quite shocking to me as I am seeing the organisation through an emotional lens"

For other students, producing a rich picture was a liberating experience, providing an opportunity of free expression. One student (see Figure 1) who worked in the public sector, drew an image of a two-lane racetrack as representing their organisation, and when asked what this represented by a member of his dialogue group replied that:

"It's the old meeting the new - you know, where the workforce is running at different speeds. Some staff are just there for the money, until they retire, sitting in dead man's shoes so to speak - their pension is their reason to exist. Others, the younger members of staff are those who want change - they have all the ideas, the innovative projects"

The concept of an organisation as creating a "brick wall" also featured in one of the images. This student, who worked in the National Health Service, when asked about her image, conceived her working environment as being one that stopped new ideas from rising to the top - a brick wall (see Figure 2) separated the management from the "rest":

"It's so frustrating - the managers sit behind this brick wall, make decisions, and throw out commands, issue new procedures, and rules, and the meetings they attend, well it's all blah, blah, blah. They can't see the chaos they have created below them; in fact I don't think they care". They play silly games by miscommunication of their edicts by playing one department off with another - you know - silo management"

Another student who also worked in the National Health Service, and was intending to study power structures in her organisation produced an image of a farmyard, and when asked why this typified her organisation by a member of the her dialogue group likened it to an Orwellian organisation where:

"My organisation is divided between the elites and the rest. Those at the bottom of the pile are drowning just drowning because they lack oxygen to breath, think, and act - they are reduced to robots that can be manipulated by those from above. If the management would only look, they would see cries for help from those who do all the front-line work - it's madness. Producing an image in this way has given me an alternative way to unlock how I think and perceive my workplace - having the freedom to draw an image of my organisation has allowed me, no given me a kind of permission to think and say what I really think of my organisation"

Another student, who worked in the private sector for a technology company drew an image of his organisation accompanied by narrative (see Figure 3), but this revealed why he thought his organisation was struggling to keep its competitive edge. One image he produced was that of a tree, which for him represented an old established company, with a large wealth of corporate knowledge, but it was also surrounded by a fence, which represented an organisation that was becoming more isolated as new technologies advanced, and a reluctance to branch out. As he suggested in his dialogue group:

"We work in a competitive market, and increasing competition - it's an uphill struggle (referring to another image he had also produced of his organisation). There is clash of traditional values with new ways of doing things, where our products are vastly over engineered, and we don't seem to be able to get those with 
the old technology mentality with the new technology mentality - it's all to with poor internal communication".

A student who worked in the university sector in a central support unit drew a simple, yet for them a powerful image (see Figure 4) as she explained in her dialogue group:

"Well, my image depicts the schizophrenic organisation - it wants success on all fronts - the trouble is that neither the academic or support staff are communicating in an integrated manner what they actually mean by success - they both have different views of success - and the double headed figure? Oh, that's me - not knowing which way to turn, which direction I'm supposed to follow - I am so confused in all the chaos - its chaos. I often think, what's the point, and who really cares? I'm just a number - someone who has been asked to a job against all the odds - its chaos"

\section{Implications for organizational and management learning practice}

Senge (1990) recognised that creativity founded within dialogical practices was essential to individual and group learning, and creating what he called a shared vision of organisational life. As Senge (1990:10) notes 'The discipline of team learning starts with dialogue, the capacity of members of a team to suspend assumptions and enter in a genuine "thinking together' and it is 'The discipline of dialogue involves learning how to recognise the patterns of interaction in teams that undermine learning'. This has impacts upon knowledge creation and the concept of the reflexive turn. For example, Calas and Smircich (1992:240) speak of reflexivity that constantly assesses the relationship between "knowledge" and the ways of "doing knowledge". This implies that serious attention is paid to the way different types of social, political, and cultural issues are woven together in the process of knowledge development, during which empirical material is constructed, interpreted, and written. According to Roebuck (2007) reflexive and reflective practice together can be described as a process of inquiry which facilities appreciation and understanding of contextualised views, a deeper learning experience, the development of ideas, and conditions for actual change. Furthermore, Cunliffe (2004) notes that reflexivity is a process where 'Critically reflexive practice embraces subjective understandings of reality as a basis for thinking more critically about the assumptions, values, and actions on others'. According to Cunliffe (2004:407) reflexive practice is therefore important because 'it helps us understand how we constitute our realities and identifies in relational ways, and where we can develop more collaborative and responsive ways of managing organizations'. Cunliffe (1999:8) suggests critical theory draws on social constructionist suppositions that we construct social realties between us in our interactions (Prasad and Caproni, 1997) and that 'organisational realities and identities are interwoven in a continuous process of mutual construction; we co-construct our realities in our conversations. Accordingly our knowledge of the world is also constructed through interaction because we make sense of what is happening around us as we engage in dialogue, reflection, and reflexive practice (see, for example, Armitage, 2010 and 2011). As Glass (2001:21) notes human beings inhabit, and are inhabited by, the structures, institutions, social relations, and self-understandings that comprise a people's culture, and that:

'The practice of freedom, as critical reflexive practice, must grasp the outward direction, meaning, and consequences of action, and also its inward meaning as a realization and articulation of the self. Therefore, education as a practice of freedom must include a kind of historic-cultural, political psychoanalysis that reveals the formation of the self and its situation all their dynamic and dialectical relations'.

Freire contends that people must first (critically) recognize how their reality comes into being so that their 'transforming action can create new realities, which makes possible a fuller humanity' (Freire, 1972:29). Critical reflection is central to understanding reality, and an individual's relationship with the world and 'Consciousness is constituted in the dialectic of man's objectification of and action upon the world. However, consciousness is never a mere reflection of, but is a reflection upon material reality' (Freire, 1972:53). The process of conscientization has two central features: dialogue and problematization, and Freire (1972) describes the process of conscientization as having three stages, whereby individuals move from magical, to naive, and finally to critical consciousness. For Freire conscientization is a dialectic of reflection and action, and the gaining of critical consciousness will not of itself transform the world, and as Freire (1972:47) notes 'this discovery cannot be purely intellectual but must involve action; nor can it be limited to mere activism, but involve serious reflection'. Furthermore, conscientization is not purely one of individual development, as is must be located within the context of the collective, in mutually supportive horizontal relationships. According to Bolton (2001) effective reflective practice is a dynamic and challenging process, and requires those who partake in its process learn to question reflexively, through dialogue, their personal and professional practices, and the impact these will have on the wider society and individuals they interact with, and Steier (1995:163) notes, reflexivity is when 'we contextually recognise the various mutual 
relationships in which our knowing activities are embedded'. As Senge (1990:245) states 'Seeing each other as colleagues is critical to establish a positive tone and to offset the vulnerability that dialogue brings. In dialogue people actually feel they are building something, a new deeper understanding'. This it can be argued this is critical for organisational dynamics that support openness and supportive cultures of exploration, and that 'The "compartmentalization of knowledge" creates a false sense of confidence. For example, the traditional disciplines that influence management....divide the world into neat subdivisions within which one can often say, "This is the problem and here is the solution"....Life comes to us as whole' (Senge, 1990:263). This is has resonance to Bolton's (2001:7) argument that 'stories are imaginative creations drawn from experience. Seen as a set of interlocking plots, the problems, anguishes and joys of practice become comprehensible - material to be dealt with creatively and developmentally. The use of the aesthetic imagination in creating this material provides a screen as wide as life itself, drawing upon all the practitioner's faculties. Attempting to reflect only "what actually happened", and then to subject such an account to rational questions such as "how might I have done it better", unnecessarily restricts what might be explored'. As such, if new imaginative awakenings are to be sought within organisational settings and to challenge cultures of silence, and are to be embodied within management practices then a culture of openness has to be inculcated in the workplace, one that takes into account all stakeholder perspectives of those who problematize their particular issues and will ultimately own the solutions to their problems. The genesis of such problematization commences with generative themes (Freire, 1970) that are created in the imaginative movement of those individuals who are in need of creative solutions in response to meet the needs of organisational demands, as Senge (1990:278) when referring to the problematization of issues notes 'When this happens, participative openness can become a "symptomatic solution". Then it shifts the burden away from the "fundamental solution" to reflective openness in developing the skills of inquiry, reflection, and dialogue'.

\section{Conclusions}

The purpose of this paper was to challenge the traditional methods of gaining access to organisational realties via the dialogical imagination and the use of image work. As such, imagination, whilst the place of completeness, is also the place of new beginnings, where the world can be "re-oralised" as it unfolds other, and hidden realities (Greene, 2003:23). Whilst I have presented an example of how art and dialogue can be combined to produce powerful images of organisational reality, my main objective was to set out an alternative (radical) proposal for introducing the dialogical imagination as a way to explore hidden realities of organisational life at the commencement of the research process. It is hoped that teachers and organisational researchers will develop their own radical and imaginative techniques to stimulate authentic student responses to organisational problems. It can be argued that the approach I am advocating has wider utility, for example as a data collection tool with respondents, and the production of narratives and auto-ethnographic accounts. I therefore invite those who share the sentiments articulated here to consider two fundamental questions: Does a methodology of the imagination have a place within management and organisational research? Is it possible to devise and design more sophisticated methodological tools to explore the inner realities of organisational life? My hope is that these questions will be the catalyst to stimulate and extend to a wider, deeper, and insightful debate to inform management and organisational research practice.

\section{References}

Alvesson, M. and Deetz, S. (2000). Doing Critical Management Research, London: Sage.

Alvesson, M. and Skoldberg, K. (2000). Reflexive Methodology, London: Sage.

Angelo, M. (2005). Splendor Solis: Inviting the Image to Teach, Harvest, Vol. 51, No.2.

Armitage, A. (2010). From sentimentalism towards a critical HRD pedagogy, Journal of European Industrial Training, 34, 8/9, 735-752. http://dx.doi.org/10.1108/03090591011080940

Armitage, A. (2011). Critical Pedagogy and Learning to Dialogue: Towards Reflexive Practice for Financial Management and Accounting Education, The Journal for Critical Education Studies, 9, 2, 104-124.

Bachelard, G. (1938). The Formation of the Scientific Mind, (Trans.) Mary, McAllester Jones, Manchester: Clinamen Press.

Bachelard, G. (1958). The Poetics of Space, Trans. John, B. Stilgoe, Boston: Beacon Press.

Bachelard, G. (1970). The Right to Dream, Dallas: The Dallas Institute Publications.

Boal, A. (1974). Theatre of the oppressed, London: Pluto Press.

Bohm, D, Factor, D and Garrett, P. (1991). Dialogue: A proposal, http://world.std.com/ lo/bohm/0000.html 
Boje, D. and Al Arkoubi, K. (2009). 'Critical Management Education Beyond the Siege' in Armstrong, S and Fukami, C. The Sage Handbook of Management Learning, Education and Development London: Sage.

Bolton, G. (2001). Reflective Practice, London: Sage.

Calas, M. and Smircich, L. (1992). Writing gender into organizational theory: directions from feminist perspectives. In M. Reed and M. Hughes (Eds.) Re-thinking organizations: New directions in organisational theory and analysis, London: Sage.

Calvino. (1998). The Six moments for the millennium, London: Penguin.

Cunliffe. (1999:8). Critical Pedagogy: Reflexive Dialogical Practice. In Management Learning, Critical Management Studies Conference, University of Manchester, 14-16 July.

Cunliffe, A. L. (2004). On Becoming a Critically Reflexive Practitioner, Journal of Management Education, 28 No. 4, 407-426. http://dx.doi.org/10.1177/1052562904264440

Detert, J.R. and Edmondson, A. (2006). Everyday failures in organisational learning: Examining the high threshold for speaking up at work. Working paper no.6-024, Harvard Business School, Cambridge, MA.

Edwards, M.S. and Gardner, J. (2007). The role of emotions in employees' decisions to report or remain silent about serious wrongdoing . In J Greenberg and M.S. Edwards (chairs), The role of emotion in individual decision-making. Symposium presented at the annual meeting of the Academy of Management, Philadelphia, PA.

Fourastie, B. and Joron, P. (1993). The imaginary as sociological perspective, Current Sociology, 41(2):53-58. http://dx.doi.org/10.1177/001139293041002007

Freire, P. (1970). Pedagogy of the oppressed. London, Penguin.

Freire, P. (1972). Cultural Action for Freedom, London: Penguin.

Freire, P. (1998). Pedagogy of Freedom, USA: Rowman \& Littlefield

Gaudin, C. (2005). Gaston Bachelard: On Poetic Imagination and Reverie, Connecticut: Spring Publications.

Giroux, A.H. (1988). Teachers as intellectuals, London: Bergin and Garvey.

Glass, R. D. (2001). On Paulo Freire's Philosophy of Praxis and the Foundations of Liberation Education, Educational Researcher, 30, 2,15-25. http://dx.doi.org/10.3102/0013189X030002015

Greenberg, J. and Edwards, M.S. (2009). Voice and Silence in Organisations, San Diego CA: Elsevier

Greene, M. (1978). Landscapes of learning, New York: Teachers College Press.

Kent, L. (2003). Lucio Pozzi: Diagrams, Italy: Edizioni Bacacy.

Lalli, P. (1989). The imaginative dimension of everyday life: towards a hermeneutic reading, Current Sociology, 37(1):103-114. http://dx.doi.org/10.1177/001139289037001011

Latta, M.M. (2004). Traces, Patters, Texture: In Search of Aesthetic Teaching/Learning Encounters, in David, M. Callejo Perez, Stephen, M. Fain. and Judith. J. Slater. (Eds.) Pedagogy of Place, New York: Peter Lang.

Linstead, S. and Höpfl, H. (2000). The Aesthetics of Organisation, London: Sage.

Marcuse, H. (1978). The aesthetic dimension, Boston: Beacon.

McCowon, T. (2006). Approaching the political in citizenship education: The perspectives of Paulo Freire and Bernard Crick, Educate, Vol.6, No.1, pp. 57-70.

Milliken, F.J., Morrison, E.W. and Hewlin, P.F. (2003). An exploratory study of employee silence. Issues that employees don't communicate upward and why. Journal of Management Studies, 40, pp.1453-1476. http://dx.doi.org/10.1111/1467-6486.00387

Mitchell,W.J.T. (1994). Picture theory: Essays on verbal and visual representation, Chicago: University of Chicago Press.

Morrison, E.W. and Rothman, N. (2008). Silence and the dynamics of power. In J. Greenberg and M.S. Edwards (2009) Voice and Silence in Organisations, Vol.6, pp.111-134, San Diego CA: Elsevier.

Patton, M.Q. (2002). Qualitative Research and Evaluation Methods, London: Sage.

Prasad and Caproni. (1997). Critical Theory in the Management Classroom: Engaging Power, Ideology, and Praxis, Journal of Management Education, 21(3), 284-291. http://dx.doi.org/10.1177/105256299702100302 
Premeaux, S.F. and Bedian, A.G. (2003). Breaking the silence: The moderating effects of self-monitoring in predicting speaking up in the workplace. Journal of Management Studies, 40, pp.1537-1562. http://dx.doi.org/10.1111/1467-6486.00390

Ragsdell, G. (2000). Engineering a paradigm shift? An holistic approach tp organisational change management, Journal of Organizational Change Management, 13, Issue 2:104-122. http://dx.doi.org/10.1108/09534810010321436

Ricoeur, P. (1975). Lectures on Imagination, University of Chicago (unpublished), in Georg, H. Taylor.

Ricoeur's Philosophy of Imagination, Journal of French Philosophy, 16, Number 1 and 2, Spring-Fall, 2006.

Roebuck, J. (2007). Reflexive practice: To enhance student learning, Journal of Learning Design, 2, 1, 34-39.

Ryan, J.W. (1974). Paulo Freire, Literacy Through Conscientization, International Institute for Adult Literacy Methods.

Senge, P. (1990). The fifth discipline, London: Random House.

Shor, I. and Freire, P. (1987). A Pedagogy for Liberation, Massachusetts: Bergin and Garvey Publishers.

Slater, J.J. (2004). The Erosion of the Public Space, in David, M. Callejo Perez, Stephen, M. Fain. and Judith, J.

Slater. (Eds.) Pedagogy of Place, New York: Peter Lang.

Steier, F. (Ed.) (1995). Research and Reflexivity. London: Sage Publications.

Sullivan, G. (2005). Art Practice as Research, London: Sage.

Tacussel, P. (1993). Imaginary and social aesthetics: epistemological proximity, Current Sociology, 41/42:33-42. http://dx.doi.org/10.1177/001139293041002005

Uhrmacher, B. (2004). An Environment for Developing Souls: The Ideas of Rudolf Steiner." 2004. In D. Callejo Perez, S. Fain and J. Slater (Eds.). Pedagogy of Place: Seeing space as cultural education. New York: Peter Lang.

Voss, A. (2009). A Methodology of the imagination, Eye of the Heart: Journal of Traditional Wisdom, 3: 37-53.

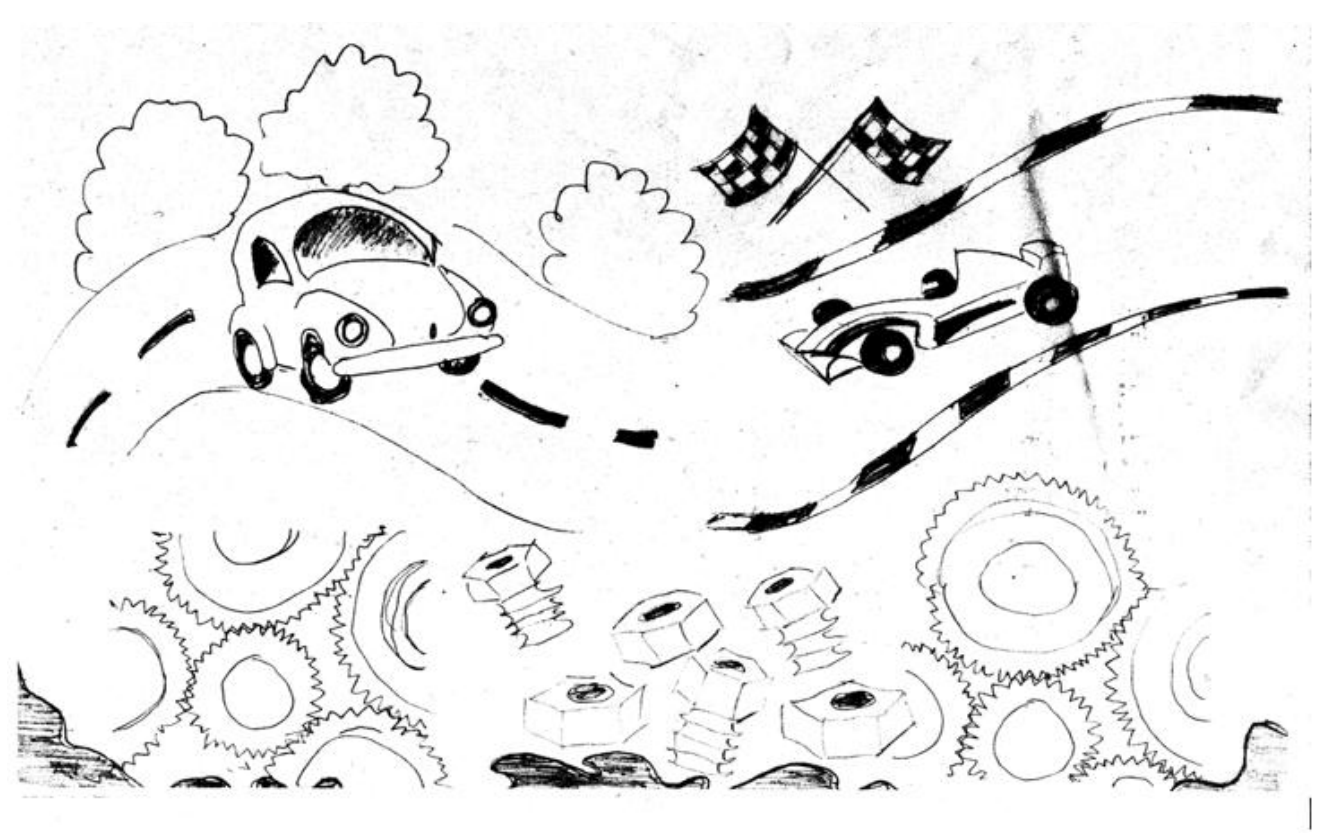

Figure 1. Image from a student working in the public sector 


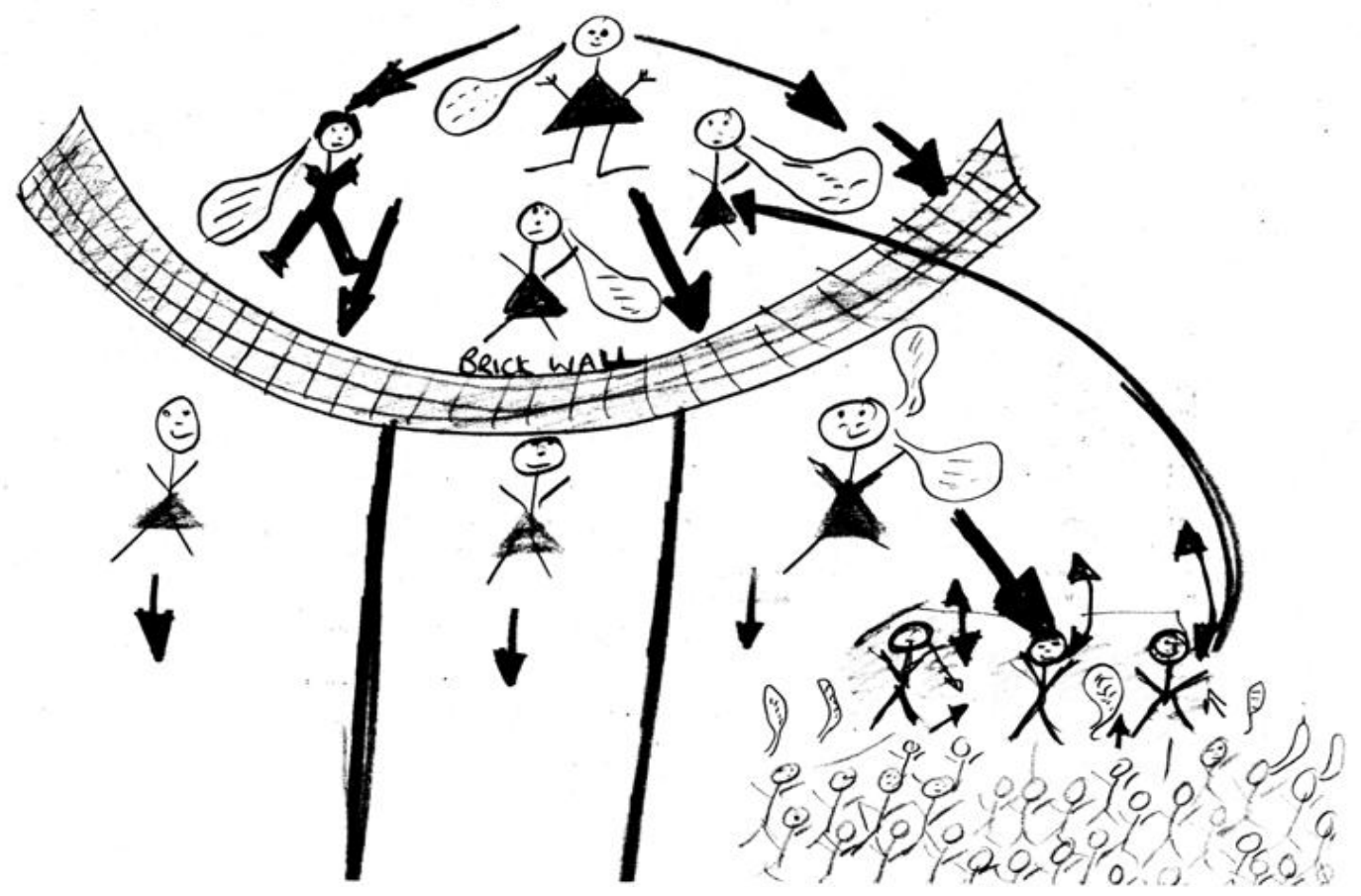

Figure 2. Image from a student working in the National Health Service

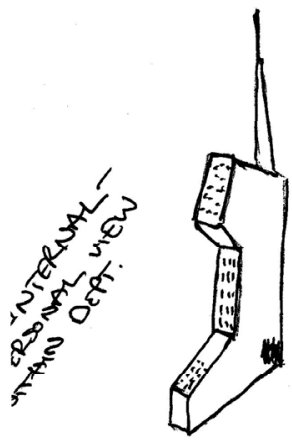

Old qnew

-technology dhanging)

Costly Over-Engiveared products

Reluctamce to charnge

combination of Modern

rechnologs and tradutional

ihily vatues

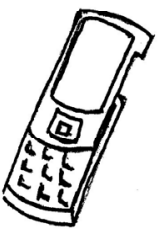

- Uphul stinggre

- Saturaded Market

- Increarsing competition

- Difficulat to remain 1
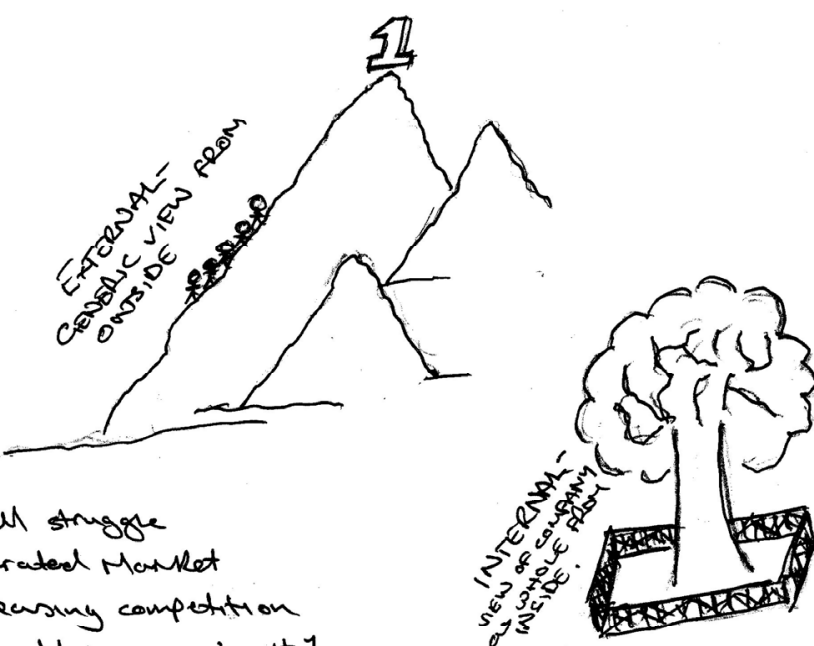

- Old tree (e stablished

- lange wealth of Rmowlege

- Isolated (Picket fence)

- Reluctance to 'bromch' out and explore new arenvers.

Figure 3. Image from a student working in the private sector for a technology company 


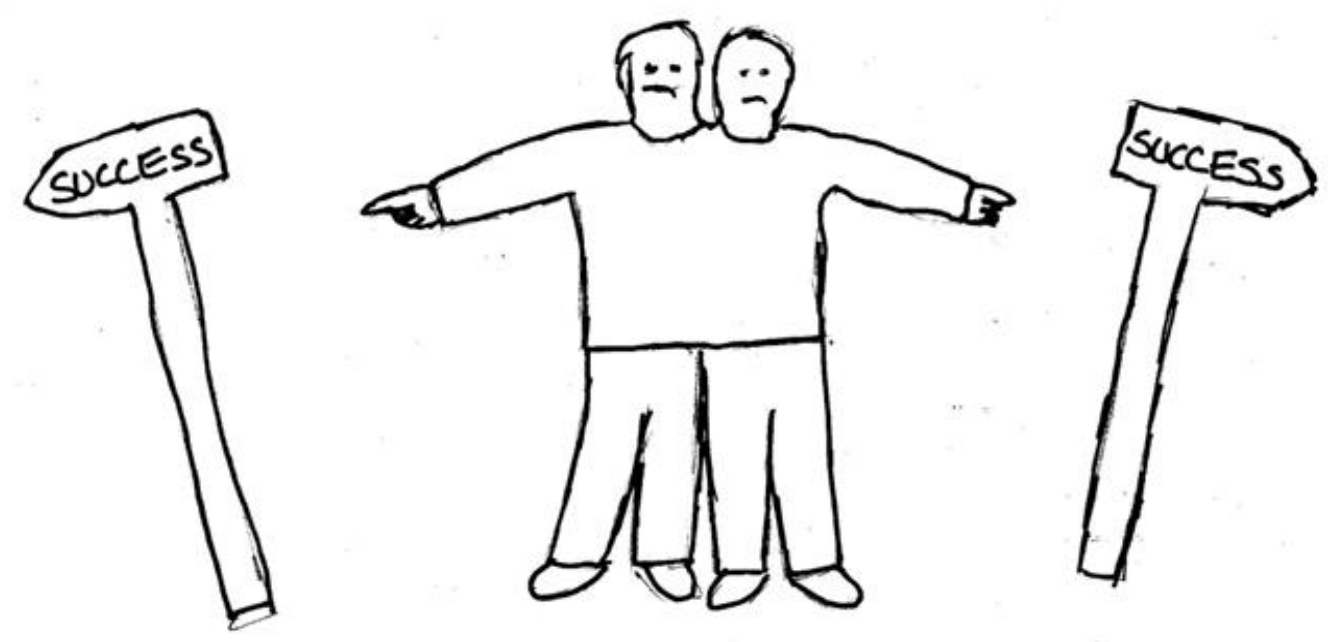

Figure 4. Image from a student who worked in the university sector 